\title{
Influence of Top Management Supports on Informationization Performance: Based on the Mediating Role of Informationization Strategy
}

\author{
Ming Zhong ${ }^{1} \&$ Fuangfa Amponstira ${ }^{2}$ \\ ${ }^{1}$ Ph.D. Candidate, Management, School of Management, Shinawatra University, Thailand \\ ${ }^{2}$ Management, School of Management, Shinawatra University, Thailand \\ Correspondence: Ming Zhong, Management, School of Management, Shinawatra University, Thailand. \\ Fuangfa Amponstira, Management, School of Management, Shinawatra University, Thailand.
}

Received: September 23, 2021

Accepted: October 9, 2021

Online Published: October 19, 2021

doi:10.5539/ibr.v14n11p71

URL: https://doi.org/10.5539/ibr.v14n11p71

\begin{abstract}
Based on cognitive theory and high-level echelon theory, this paper studies the impact of executive support on the performance of enterprise informatization. Constructed the relationship model of corporate executive support, informatization strategy and informatization reform. Through a questionnaire survey of enterprises in Guangdong Province, China, a total of 420 valid questionnaires was collected, and the data were empirically analyzed using SPSS25 statistical software. The paper found that: executive support positively affects enterprise information performance. Information strategy positively affects enterprise information performance. Information strategy has an intermediary effect between executive support and information performance. This paper helps to understand the mechanism of executive support and informatization performance in-depth, enhance the support of executives to informatization management, and provide relevant suggestions for the development of enterprise informatization.
\end{abstract}

Keywords: top management supports, informationization performance, informationization strategy

\section{Introduction}

Informatization not only brings opportunities for the development of enterprises but also brings a lot of challenges, enterprises must attach great importance to the cautious response. From a macro point of view, the role of informatization is reflected in: it is conducive to adapt to the internationalization of competition, enhancing the sustainable and rapid development of the country's economy, and improving the country's comprehensive strength.it is a necessary prerequisite for enterprises to achieve cross-regional, especially multinational operations. It is conducive to the collection, sharing and dissemination of information. It is conducive to strengthening the technical communication between different enterprises, thereby improving the overall technical level of the industry. From a Meso point of view, the role of informatization is reflected in: it helps most companies improve their management models and achieve scientific and efficient management. It helps to improve product design and production efficiency, reduces inventory, and saves capital, and obtains in time. Customer demand, shorten the service response time and realize the production according to order. Increase the capital circulation rate, realize the efficient use of capital, can greatly increase the rate of information dissemination in the enterprise, and promote the popularization and use of information technology. From a micro point of view, the role of informatization is reflected in: reducing the labor intensity of employees, replacing repetitive and routine manual labor with automation, and increasing the value of employees' mental labor, the smooth flow of information is also conducive to the development of employee relationship management.

In China, information has become a hot spot for governments and enterprises. The state and the government have introduced several policies to promote the improvement of the level of enterprise information. For the efforts of enterprises to promote information, the main tasks of the enterprise are hardware construction, software development, training and use of talents, and the creation of an information atmosphere.

Executive support is more about the work content that affects the corporate informatization strategy. Top 
management support is the "power source" for enterprise information transformation. Information has a profound impact on the operation of enterprises. Therefore, information construction necessarily involves people at all levels of decision-making, management, and executive levels within the enterprise. Among them, senior managers of enterprises are particularly critical to the success of information construction.

\section{Theory and Hypotheses}

From the perspective of social psychology, scholars have used cognitive theory, high-level echelon theory, and institutional isomorphism theory to study the relationship between executive support and informatization.

\subsection{Cognitive Theory}

Cognitive theory mainly studies how to induce behavior changes through individual experience. Research in this field attaches great importance to individuals' subjective cognition of their situation, and regards mental activities and thinking processes as internal information processing processes. It also pays attention to the influence of internal thinking processes on behavior. Therefore, the cognition and behavior of corporate members are mainly determined by the way they know the world and behave in the world, and the way of thinking determines their inner experience process and behavioral response. Lefebvre et al. (1997) proposed that the level of participation of senior managers is often determined by their subjective understanding of informatization rather than objective conditions. The higher the level of recognition, the greater the willingness to participate in the practice of informatization. Liang et al. (2007) believed that senior management's awareness of the use and value of ERP can affect their enthusiasm for participating in ERP projects. Conversely, the higher the level of participation of senior managers in informatization, the deeper their understanding of the value of information technology. Therefore, actively improving the knowledge of information factors and technology of senior managers will help them to adopt behaviors that are conducive to the construction of enterprise informatization and create a good informatization atmosphere.

\subsection{High-level Echelon Theory}

In 1984, Hambrick and Mason proposed the "high-level echelon theory." The theory believes that companies are faced with complex internal and external environments, and it is impossible for executives to fully understand everything around them and can only observe selectively. Therefore, the existing values and knowledge structure of top managers will significantly affect their interpretation of what they observe. In other words, the strategic decision-making process of senior managers and their judgment on the results of informatization. Given this, scholars in the field of information have proposed that executive support is an important component of organizational support in the implementation of enterprise information systems. However, because psychological traits are difficult to measure directly, demographic characteristics, such as age, tenure, education level, etc., are easier to measure objectively and will have a significant impact on the cognitive abilities and values of executives. Therefore, many studies have paid attention to the relationship between the demographic characteristics of executives and the construction of enterprise informatization. From previous studies, in general, young, extroverted, democratic, and senior managers with relevant learning and work experience have made greater contributions to enterprise informatization (Chen Xiaochun, 2012).

\subsection{Top Management Supports and Informationization Performance}

When studying the main influencing factors of informatization, scholars found that the level of executive support is the main factor that determines the success or failure of informatization projects. Nah et al. (2007) summarized 11 main factors that affect the implementation of enterprise ERP projects through a review of previous documents. The problem of insufficient executive support is mentioned in each article, and other factors are also directly or indirectly affected by senior managers. Zhang Zhe et al. (2005) found through multiple case studies that the support of executives is sufficient to influence the success of Chinese enterprises' informatization. Bai Haiqing et al. (2011) pointed out that even after the information system goes online, the support of executives is crucial for the absorption of information technology. Li Li et al. (2010) believe that the impact of senior management support on informatization is reflected in the value judgment of senior management on information technology, which will affect the value judgment of other members of the company on the use of information technology. Senior management support can make the enterprise informatization. The system is becoming more perfect and promotes the value recognition of middle-level managers and grassroots employees. senior managers can create a good informatization atmosphere in the company to enable company members to respond to informatization changes with a more positive attitude and face more calmly various obstacles. Studies have proved that the level of support from senior management can affect the enthusiasm of other members of the enterprise to invest in information construction (Yong et al., 2013). Executive support can provide a resource guarantee for informatization (Tangpong, 2021). Senior managers have a clear understanding of informatization 
and can help them correctly estimate the investment required for informatization projects, including funds, time, data, and other resources, to provide adequate resource protection (Jung et al., 2003). Executive support can promote the matching of information technology and business planning (He Lijun et al., 2010).

Based on the above analysis, this paper proposes the following hypotheses:

H1: Top Management Supports has a significant impact on Informationization Performance.

\subsection{Top Management Supports and Informationization Strategy}

Senior managers should pay attention to the dynamics of enterprise informatization, do a good job in informatization strategy formulation and organizational -term planning, use information technology as a tool to promote the transformation of business models and improve the overall management level of the enterprise through changes in management systems, organizational structures, and business processes. And work efficiency (Chen Xiaochun, 2012). The first task of senior managers in the formulation of informatization strategy is to clarify strategic positioning and long-term goals (Lederer et al., 1988). Level managers must be able to understand informatization from the perspective of strategic development, establish an important position of informatization, and effectively integrate informatization construction with enterprise systems, business operations, and management development (Hu Xiaoming, 2012). On the one hand, corporate executives must have an accurate positioning of the informatization development strategy, so that it can be consistent with the corporate strategic direction, can support the corporate strategy, reflect the company's resource constraints and development opportunities, and be able to guide corporate mission planning (Booistra, 2013). On the other hand, companies need to implement informatization target management to guide employees in the right direction. Senior managers and subordinates jointly negotiate and formulate enterprise informatization development goals, clearly express their expectations for employees, define the tasks they need to complete, and formulate implementation standards (Rachael, 2008).

Based on the above analysis, this paper proposes the following hypotheses:

H2: Top Management Supports has a significant impact on Informationization Strategy.

\subsection{The Mediating Role of Informationization Strategy}

It can be seen from the acquisition process of informatization performance that the informatization transformation strategy plays an intermediary role between the support of senior management and informatization performance. The ideas and behaviors of senior managers firstly act on the information strategy and then affect the enterprise's information performance. He Lijun et al. (2010) believe that executives' support affects the company's informatization performance by influencing the management and control of the enterprise information system, the strategic positioning of the information system, the degree of CIO's participation in business planning, and the matching between the information system and the business. Executive support is the foundation for formulating informatization strategies and improving management systems. Enterprise informatization involves several organizational changes, such as organizational structure adjustments, process transformations, etc., which will inevitably be resisted by some corporate members. Senior managers are required to improve this problem through strategic and institutional changes (King, 2008). The support of senior managers for informatization strategy is mainly reflected in strategic planning and supervision and implementation, including strategic positioning, strategic planning, informatization target management, etc. (Kearns, 2006). Senior managers can also guide and inspire employees to change their understanding of informatization by adjusting the organizational structure and management system of the enterprise. The main management changes involved in Chinese enterprises include the reform of incentive systems, the construction of training systems, and the guarantee of resource allocation (Chen Xiaochun, 2012). Chen Xiaochun et al. (2012) integrated the research content of the TAM model and the D\&M model in the field of technology adoption based on summarizing previous studies and proposed a research framework for executive support. The model realizes executive support that affects the effect of informatization mainly through two paths: First, executive support affects their perceptions of the usefulness and ease of use of information technology and then affects their attitudes and intentions towards informatization. Affect the absorption and acceptance of information technology, and ultimately improve the possibility of successful project implementation and informatization performance. On the other hand, executive support will encourage the information technology department to pay attention to the quality of the information technology used and the quality of the internal information transmission and processing of the enterprise, improve user satisfaction, and enhance the impact of the use of information systems on individuals and organizations, thereby increasing The possibility of successful implementation of informatization projects and the information performance of the enterprise. Therefore, executives can improve the company's informatization performance by formulating strategies that include information technology and 
informatization quality.

Based on the above analysis, this paper proposes the following hypotheses:

H3: Informationization Strategy mediates the relationship between Top Management Supports and Informationization Performance

\section{Methodology}

\subsection{Data Collection}

This paper mainly selects listed companies in Guangdong Province as a sample. The empirical data obtained from the paper mainly comes from the questionnaire survey. The main ways of questionnaire distribution are as follows: First, the author issues questionnaires through personal relationships and asks students, colleagues, and friends to distribute them on their behalf. Second, the Chinese doctoral tutor contacts the Guangdong CIO Alliance. Third, through the alumni relationship, China Ping An Insurance, China Southern Power Grid, and other large groups. The company investigates its subsidiaries. Because the subsidiary's main business and the information system used are different, each subsidiary can be considered as a different sample.

The main target of this questionnaire is the management personnel of the enterprises that have applied the information system, and they hope that these people have been working in the current business for more than 2 years, mainly because they understand the business philosophy of senior managers better than ordinary employees. Daily activities are dynamic and have experience in using information systems to make more accurate judgments and assessments of the use of information systems. A total of 450 questionnaires were distributed in this paper, and 420 were eventually returned, with a recovery rate of $93 \%$.

\subsection{Questionnaire Design and Measurement}

This paper screened the results of the questionnaire in a variety of ways to ensure that the data is valid. First of all, this book has set up a reversal question in the questionnaire, which can better judge whether the attitude of the respondent is serious. Secondly, most of the questionnaires in the pre-investigation phase are filled in by familiar and reliable respondents. Basically, the duration of the questions can be determined. Based on the questionnaires that respond to the star-links of the questionnaires, it is found that most of the questionnaires that are too short-lived are invalid. Again, in order to prevent the respondent from filling in multiple times, the number of responses to the same terminal is limited to 1 , and only one copy of the questionnaire displayed as the same IP is selected as the valid questionnaire. Finally, this questionnaire is designed to ask questions about the level of work and the number of years of work in the enterprise. The average employee's answer within one year of the company's work is regarded as an invalid questionnaire, avoiding the business philosophy and daily activities of senior management. Dynamic, and the situation of misjudgment that occurs when the informationization of the enterprise is not well understood.

The author used a semi-constructed survey questionnaire to collect the data from the samples. The questionnaire has three parts including personal profile, enterprise information, and the main part of questionnaire. Part One, Personal profiles collected the personal data of the respondents, which including a total of six questions Part Two, Enterprise Questions collected the basic information which included a total of five questions. Part three, Scaled Questions collects the data to be measured for the independent variables, Mediate variables, and Dependent variables, which includes a total of 25 questions.

\section{Data Analysis and Results}

\subsection{Descriptive Statistics Analysis}

As shown in Table 1, the proportion of women surveyed is slightly higher $(52.38 \%)$, and most of them are between 21-40 ages, accounting for 72.18\%. The subjects have relatively high academic qualifications, of which only 19 persons are under the junior college degree, accounted for 4.52 percent of the total sample. Bachelor degree or above accounts for $70 \%$. There are 103 middle and senior managers, accounting for $24.52 \%$, and 284 employees. Most respondents have 2-4 years of work experience, accounting for $64.55 \%$. The nature of the company is mainly private, accounting for $58.57 \%$. The number of years that enterprises use information systems is mainly concentrated in 3-4 years, accounting for $40.95 \%$. 
Table 1. Demographic Profile of the Respondents Descriptive Results

\begin{tabular}{|c|c|c|c|}
\hline \multicolumn{2}{|c|}{ Demographics Characteristics } & \multirow{2}{*}{$\frac{\text { Frequency }}{200}$} & \multirow{2}{*}{$\frac{(n=420)}{47.62 \%}$} \\
\hline \multirow{2}{*}{ Gender } & Male & & \\
\hline & Female & 220 & $52.38 \%$ \\
\hline \multirow{5}{*}{ Age } & $\leq 20$ & 13 & $3.10 \%$ \\
\hline & $21-30$ & 75 & $17.86 \%$ \\
\hline & $31-40$ & 188 & $44.76 \%$ \\
\hline & $41-50$ & 87 & $20.71 \%$ \\
\hline & $>50$ & 57 & $13.57 \%$ \\
\hline \multirow{5}{*}{ Education Level } & Ph.D & 17 & $4.05 \%$ \\
\hline & Master & 104 & $24.76 \%$ \\
\hline & Bachelor & 173 & $41.19 \%$ \\
\hline & Diploma & 107 & $25.48 \%$ \\
\hline & others & 19 & $4.52 \%$ \\
\hline \multirow{5}{*}{ Position } & Senior manager & 47 & $11.19 \%$ \\
\hline & Middle manager & 56 & $13.33 \%$ \\
\hline & General manager & 33 & $7.86 \%$ \\
\hline & General Staff & 256 & $60.95 \%$ \\
\hline & Technical staff & 28 & $6.67 \%$ \\
\hline \multirow{5}{*}{ Years of Work } & $\leq 1$ year & 74 & $17.62 \%$ \\
\hline & 2-3 years & 139 & $33.1 \%$ \\
\hline & $4-6$ years & 132 & $31.43 \%$ \\
\hline & $7-9$ years & 71 & $16.9 \%$ \\
\hline & $\geqslant 10$ years & 4 & $0.95 \%$ \\
\hline \multirow{5}{*}{ Nature of the enterprise } & State-owned or holding company & 42 & $10 \%$ \\
\hline & Private enterprise & 246 & $58.57 \%$ \\
\hline & Joint venture & 37 & $8.81 \%$ \\
\hline & Foreign or joint venture & 77 & $18.33 \%$ \\
\hline & Collective enterprises & 18 & $4.29 \%$ \\
\hline \multirow{5}{*}{$\begin{array}{c}\text { Years of Use of Information } \\
\text { Systems }\end{array}$} & Less than 1 year & 81 & $19.29 \%$ \\
\hline & $1-2$ years & 112 & $26.67 \%$ \\
\hline & 3-4 years & 172 & $40.95 \%$ \\
\hline & $5-6$ years & 46 & $10.95 \%$ \\
\hline & More than 6 years & 9 & $2.14 \%$ \\
\hline
\end{tabular}

\subsection{Reliability and Validity Analysis}

This paper uses SPSS25.0 statistical software to test the reliability and validity of all variables. Since this paper uses a mature scale to test the reliability of variables through Cronbach's $\alpha$ value, as shown in Table 1, Cronbach's $\alpha$ values are all greater than 0.9 , and the CITC value is greater than 0.7 . Therefore, the reliability of the scale of this paper is good.

Table 1. Reliability Test Results

\begin{tabular}{lll}
\hline Variable & CITC & Cronbach's Alpha \\
\hline Top Management Supports & 0.825 & 0.973 \\
Informationization Strategy & 0.883 & 0.975 \\
Informationization Performance & 0.851 & 0.947 \\
\hline
\end{tabular}

The results of KMO and Bartlett' s sphericity test of the executive support, information strategy, and information performance measurement scale show that the KMO values are $0.872,0.843$, and 0.915 , respectively. The approximate chi-square values of Bartlett' s sphericity test are 769.808 and 831.758 , respectively. 1596.907 , the concomitant probability (sig) value is less than 0.05 , the spherical hypothesis is rejected, and factor analysis can be used. After using the principal component analysis method to extract the factors in the overall scale data, use the maximum variance method to rotate them to obtain the results in Table 2. It can be seen from Table 2 that the factor Loading of the item after orthogonal rotation exceeds 0.8 , and the cumulative proportion of variance reaches $79.862 \%$, which is much greater than $50 \%$. This shows that the item selected in this paper has very good structural validity. 
Table2. Factor Load Test Result

\begin{tabular}{|c|c|c|c|c|}
\hline Variables & Item Code & $\begin{array}{c}\text { Top Management } \\
\text { Supports }\end{array}$ & $\begin{array}{c}\text { Informationization } \\
\text { Strategy }\end{array}$ & $\begin{array}{c}\text { Informationizatio } \\
\text { n Performance }\end{array}$ \\
\hline \multirow{10}{*}{$\begin{array}{l}\text { Top Management } \\
\text { Supports }\end{array}$} & Q1 & 0.908 & & \\
\hline & Q2 & 0.766 & & \\
\hline & Q3 & 0.762 & & \\
\hline & Q4 & 0.688 & & \\
\hline & Q5 & 0.781 & & \\
\hline & Q6 & 0.846 & & \\
\hline & Q7 & 0.840 & & \\
\hline & Q8 & 0.875 & & \\
\hline & Q9 & 0.877 & & \\
\hline & Q10 & 0.860 & & \\
\hline \multirow{10}{*}{$\begin{array}{c}\text { Informationization } \\
\text { Strategy }\end{array}$} & S1 & & 0.784 & \\
\hline & S2 & & 0.815 & \\
\hline & S3 & & 0.843 & \\
\hline & S4 & & 0.788 & \\
\hline & S5 & & 0.808 & \\
\hline & S6 & & 0.731 & \\
\hline & S7 & & 0.820 & \\
\hline & S8 & & 0.745 & \\
\hline & S9 & & 0.848 & \\
\hline & S10 & & 0.798 & \\
\hline \multirow{5}{*}{$\begin{array}{l}\text { Informationization } \\
\text { Performance }\end{array}$} & $\mathrm{P} 1$ & & & 0.792 \\
\hline & $\mathrm{P} 2$ & & & 0.776 \\
\hline & P3 & & & 0.743 \\
\hline & P4 & & & 0.770 \\
\hline & P5 & & & 0.788 \\
\hline
\end{tabular}

\subsection{Correlation Analysis}

It can be seen in Table 3, the correlation coefficients between Top Management Supports, Informationization Strategy, and Informationization Performance are $0.458(\mathrm{P}<0.01)$ and $0.474(\mathrm{P}<0.01)$. The correlation coefficient between Informationization Strategy and Informationization Performance is 0.474 ( $\mathrm{P}<0.01)$. The results show that there is a positive correlation between the variables, and the correlation is significant, which provides support for the research hypothesis of this paper.

Table 3. Description statistics and correlation analysis of each variable

\begin{tabular}{|c|c|c|c|c|c|c|c|c|c|c|}
\hline Variables & 1 & 2 & 3 & 4 & 5 & 6 & 7 & 8 & 9 & 10 \\
\hline 1. Gender & 1 & & & & & & & & & \\
\hline 2.Age & $.253 * *$ & 1 & & & & & & & & \\
\hline 3.EL & .027 & $.258 * *$ & 1 & & & & & & & \\
\hline 4.P & $.493 * *$ & $.269 *$ & $.334 *$ & 1 & & & & & & \\
\hline 5.YW & $.723 * *$ & $.148 * *$ & $.556^{*}$ & $.845^{* *}$ & 1 & & & & & \\
\hline 6.NE & $.467 *$ & $.567 * *$ & $.468 * *$ & $.438 * *$ & $.434 * *$ & 1 & & & & \\
\hline 7.YS & $.437 * *$ & $.546^{*}$ & $.645^{* *}$ & $.549 * *$ & $.532 * *$ & $.734 * *$ & 1 & & & \\
\hline $8 \mathrm{TMS}$ & $.137 * *$ & $.029 * *$ & $.237 * *$ & $.083 * *$ & $.086 * *$ & $.643 * *$ & $.671 * *$ & 1 & & \\
\hline 9.IS & $.317^{*}$ & $.436 * *$ & $.441 * *$ & $.338 * *$ & $.447 * *$ & $.671 * *$ & $.673 * *$ & $.748 * *$ & 1 & \\
\hline 10.IP & $.285 * *$ & $.527 * *$ & $.481 * *$ & $.238 * *$ & $.582 * *$ & $.432 * *$ & $.492 * *$ & $.458 * *$ & $.474 * *$ & 1 \\
\hline
\end{tabular}

Note: $* \mathrm{p}<.05 ; * * \mathrm{p}<.01 ; * * * \mathrm{p}<.001$ 3.EL is Education Level; 4. P is Position; 5.YW is Years of Work; 6. NE is Nature of the enterprise; 7. YS is the years of use of information systems; 8 . TMS is Top Management Supports, 9.IS is Informationization Strategy, 10.IP is Informationization Performance.

\subsection{Hypothesis Test}

Table 4 summarizes the regression analysis results of Top Management Supports on Informationization Performance. Model 1 is the influence of control variables on informationization performance. Model 2 is the impact on the performance of informatization after adding the support of executives based on control variables. It can be seen from Model 2 that executive support is significant for the company's informatization performance 
( $\beta=0.749, \mathrm{p}<0.001)$. Therefore, Hypothesis 1 holds. Model 3 is the influence of control variables on the informatization strategy, and Model 4 is the influence of the control variables on the informatization strategy after adding the support of executives. It can be seen from Model 4 that executive support significantly influences the enterprise's informatization strategy $(\beta=0.258, p<0.001)$. Hypothesis 2 is confirmed. Model 6 is a mediating effect test. It adds the variable of information strategy based on Model 2 to see their impact on corporate performance. At this time, the $\beta$ value of the impact of TMS on IP has changed from 0.749 to 0.217 , which shows that the impact becomes smaller, but $\mathrm{p}<0.001$, the result is still significant. At the same time, the R2 of the model changed from 0.432 to 0.722 , a significant increase. Therefore, the informatization strategy directly acts as a partial intermediary role in executive support and informatization performance. Hypothesis 3 is verified.

Table 4 . The regression results analysis

\begin{tabular}{ccccccc}
\hline \multirow{2}{*}{ Variable } & \multicolumn{3}{c}{ IP } & \multicolumn{2}{c}{ IS } & IP \\
\cline { 2 - 7 } & Model 1 & Model 2 & Model 3 & Model 4 & Model 5 & Model 6 \\
\hline Gender & 0.009 & 0.013 & 0.012 & 0.032 & 0.009 & 0.035 \\
Age & $0.089^{* *}$ & 0.026 & 0.052 & 0.023 & $0.089^{* *}$ & 0.029 \\
EL & 0.033 & 0.114 & 0.030 & 0.063 & 0.033 & 0.121 \\
P & $0.064^{*}$ & 0.017 & $0.026^{*}$ & 0.012 & $0.064^{*}$ & 0.023 \\
YW & 0.016 & 0.021 & 0.010 & 0.019 & 0.016 & 0.026 \\
NE & $0.134^{* * *}$ & $0.095^{* * *}$ & $0.084^{* *}$ & 0.052 & $0.134^{* * *}$ & $0.074^{* * *}$ \\
YS & $0.162^{*}$ & $0.245^{*}$ & $0.383^{*}$ & 0.429 & $0.162^{*}$ & $0.154^{*}$ \\
TMS & & $0.749^{* * *}$ & & $0.258^{* * *}$ & & $0.217^{* * *}$ \\
IS & & & & & & $0.636^{* * *}$ \\
$\mathrm{R}^{2}$ & 0.023 & 0.432 & 0.012 & 0.361 & 0.023 & 0.722 \\
$\triangle \mathrm{R}^{2}$ & 0.024 & 0.436 & 0.014 & 0.356 & 0.024 & 0.496 \\
$\mathrm{~F}$ & $10.673^{* * *}$ & $120.781^{* * *}$ & $2.428^{*}$ & $84.154^{* * *}$ & $10.673^{* * *}$ & $132.583^{* * *}$ \\
\hline
\end{tabular}

Note: $* \mathrm{p}<0.05, * * \mathrm{p}<0.01, * * * \mathrm{p}<0.001$

\section{Conclusion}

\subsection{Major Findings}

This paper draws on relevant research in the fields of top management support, information strategy, and informationization performance. Based on literature review and interview survey, which including Cognitive theory, High-level echelon theory. This paper deduces the model of the influence mechanism of top management support level on enterprise's informationization performance and proposes Assumption. Collecting data through large-scale questionnaires and using SPSS25.0 for statistical analysis verified most of the hypotheses and explained that the impact of executive support on the performance of enterprise informatization.

\subsection{Theory Contribution}

The theoretical contributions of this paper mainly include three aspects. 1) From the perspective of organizational behavior, taking executive support as an independent variable and informatization performance as a dependent variable, by analyzing the management and technical characteristics of different stages of enterprise informatization, the relationship between variables involved in each stage is studied and explored The formation mechanism of informatization performance in the Chinese context. 2) Exploring the mediating role of informatization strategy variables between executive support and informatization performance, clarifying the role of informatization strategy in the implementation of informatization reform and management system of enterprises, and improving the guiding theories in the field of strategic management. 3) Drawing on relevant research in the field of technological innovation performance evaluation, evaluating informatization performance based on the perspective of business management can more effectively measure the degree of informatization's improvement in business performance and management efficiency, so as to propose a complete informatization level improvement strategy. 


\subsection{Management Contribution}

The research in this paper finds that effective measures should be taken to improve the level of executive support. Effectively improve the support of the senior management team for informatization. The investment in information technology projects is relatively large. In order to reduce risks and reduce search costs, companies are more willing to imitate successful cases in similar companies. The government should strengthen information application education, and through typical successful cases, establish high-level managers' confidence in the application of information technology, so that they are willing to invest more resources in information technology projects. Second, increase the perception of corporate employees' support for executives. At this time, it is not required that all senior executives participate in the construction of informatization, but the senior management team members involved in the construction of informatization are required to have sufficient influence and show positive willingness and behavior to support. Therefore, in general sense, young, outgoing, democratic, and senior managers with relevant learning and work experience are better candidates.

The state and government should reduce direct intervention in the decision-making of enterprise informatization. First, government departments need to reduce their direct intervention in the informatization of enterprises and shift to the gradual improvement of relevant legislation and infrastructure construction. In the recent stage, the government's main work should shift to providing external guarantees for enterprise informatization and stimulating enterprises to actively adopt information technology. From the institutional aspect, the government needs to strengthen the legislative system for e-commerce and strengthen the supervision of payment credit, commodity circulation, and network security. From a technical point of view, the government should further improve the construction of enterprise network platforms, increase its flexibility, and reduce the intangible cost of enterprise access to the platform. Second, the government should formulate service specifications and guidelines and strengthen the supervision of the software supply industry to ensure that companies have the conditions to improve the matching degree of the information systems they use with corporate management processes or specific businesses. Among them, we must pay special attention to two aspects: on the one hand, it is necessary to ensure that the serviced company can have a basis when its interests are infringed and recover losses. On the other hand, it is to avoid vicious competition in the software industry.

\section{Limitations}

Although this paper has a high value, it also provides management enlightenment for enterprise informatization. It seems that due to the limitations of the author's ability and objective resources, there are still certain limitations, and it needs to be continuously improved and deepened in future research. Mainly manifested in the following two aspects: 1) Sample aspect. Although a lot of time and energy has been spent on personnel interviews and questionnaire surveys, and the sample size obtained meets the sample size requirements of social science statistics, whether it is a large sample in the true sense is worthy of attention. In addition, although the survey subjects of this paper involve more industries, enterprises of different nature and scale, the sampling method is not a random sampling, but a convenient sampling. The samples come from economically developed areas such as Guangdong, and there are restrictions on the scale of the sample enterprises, which may limit the popularization and promotion of research conclusions to a certain extent. Therefore, future research should expand the scope of the investigation and adopt random sampling methods to improve the validity of research conclusions. 2) The subjectivity of variable measurement is strong. The data comes from the subjective judgment of the surveyed. Although the survey is restricted to the management personnel of the company or the company members with many years of work experience, the recovered data also passed the reliability and validity test, but the subjective data was used to test the cause and effect in the paper. The relationship still has certain limitations. Future research can consider using more objective measurement methods, such as long-term typical case follow-up studies.

\section{References}

Bai, H. Q., \& Mao, J. Y. (2014). The motivation of CEO's support for informatization: Stimulating conditions and promoting mechanisms. Nanhe Management Review, 17(6), 114-125.

Bai, H. Q., Cheng, J., \& Mao, T. Y. (2014). How does CEO support CIO? —-Multiple case studies on the structural power vision [J]. Management World, 7, 107-118.

Chen, X. C., He, L. J., \& Wang, Y. F. (2012). Research progress on executive support in the information environment. Technological Economy, 31(1), 121-124.

Fragale, A. R., Sumanth, J. J., Tiedens, L. Z., \& Northcraft, G. B. (2012). Breaking the ivory tower: Academic entrepreneurship in the life sciences in UK and Germany. Research Policy, 40(1), 41-54. 
https://doi.org/10.1016/j.respol.2010.09.012

Hambrick, D. C., \& Manson, P. A. (1984). Faculty Entrepreneurs and Research Productivity. The Journal of Technology Transfer, 32(3), 173-194. https://doi.org/10.1007/s10961-006-9014-y

He, L. J., Wang, Y. F., \& Zhao, Z. (2010). Research on corporate executive support and its impact on informatization performance [J]. Journal of Hebei University of Industry, 39(1), 84-87.

$\mathrm{Hu}, \mathrm{X}$. M. (2012). Construction of an evaluation system for enterprise IT control systems that dominate the hierarchical structure. Accounting Research, 2012(5), 44-49.

Jung, D. I., Chow, C., \& Wu, A. (2003). The role of transformational leadership in enhancing organizational innovation: hypotheses and some preliminary findings. Leadership Quarterly, 14(4), 525-544. https://doi.org/10.1016/S1048-9843(03)00050-X

Kearns, G. S. (2006). The effect of top management support of sisp on strategic is management: insights from the us electric power industry. Omega, 34(3), 236-253. https://doi.org/10.1016/j.omega.2004.10.008

King, W. R. (2008). Including the CIO in top management. Journal of Information Systems Management, 25(2), 188-189. https://doi.org/10.1016/10.1080/10580530801941256

Lefebvre, L. A., \& Lefebvre, R. M. (1997). The influence prism in smes: the power of ceosl" perceptions on technology policy and its organizational impacts. Management Science, 43(6), 856-878. https://doi.org/10.2307/2634627

Liang, H., Saraf, Nilesh, Hu, Q., \& Xue, Y. (2007). Assimilation of enterprise systems: the effect of institutional pressures and the mediating role of top management. MIS Quarterly, https://doi.org/10.1016/j.hitech.2015.09.001

Tangpong, C., Lehmberg, D., \& Li, Z. (2021). Ceo replacement, top management vacancy, and the sequence of top management team changes in high technology turnaround companies. Long Range Planning, 1, 102103. https://doi.org/10.1016/j.lrp.2021.102103

\section{Copyrights}

Copyright for this article is retained by the author(s), with first publication rights granted to the journal.

This is an open-access article distributed under the terms and conditions of the Creative Commons Attribution license (http://creativecommons.org/licenses/by/4.0/). 